\title{
A model simulation of Pinatubo volcanic aerosols in the stratosphere
}

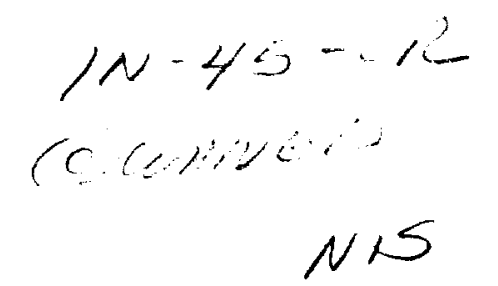

Jingxia Zhao

Department of Meteorology. School of Ocean and Earth Science and Technology, Liniversity of Hawaii. Honolulu

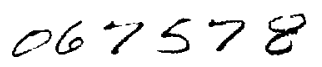

Richard P. Turco

Department of Atmospheric Sciences, University of California, Los Angeles

Owen B. Toon

NASA Ames Research Center, Moffett Field, California

\begin{abstract}
A one-dimensional, time-dependent model is used to study the chemical, microphysical, and radiative properties of volcanic aerosols produced by the Mount Pinatubo eruption on June 15, 1991. Our model treats gas-phase sulfur photochemistry, gas-to-particle conversion of sulfur, and the microphysics of sulfate aerosols and ash particles under stratospheric conditions. The dilution and diffusion of the volcanic eruption clouds are also accounted for in these conditions. Heteromolecular homogeneous and heterogeneous binary $\mathrm{H}_{2} \mathrm{SO}_{4} / \mathrm{H}_{2} \mathrm{O}$ nucleation, acid and water condensational growth, coagulation, and gravitational sedimentation are treated in detail in the model. Simulations suggested that after several weeks, the volcanic cloud was composed mainly of sulfuric acid/water droplets produced in situ from the $\mathrm{SO}_{2}$ emissions. The large amounts of $\mathrm{SO}_{2}$ (around $20 \mathrm{Mt}$ ) injected into the stratosphere by the Pinatubo eruption initiated homogeneous nucleation which generated a high concentration of small $\mathrm{H}_{2} \mathrm{SO}_{4} / \mathrm{H}_{2} \mathrm{O}$ droplets. These newly formed particles grew rapidly by condensation and coagulation in the first few months and then reach their stabilized sizes with effective radii in a range between 0.3 and $0.5 \mu \mathrm{m}$ approximately one-half year after the eruption. The predicted volcanic cloud parameters reasonably agree with measurements in term of the vertical distribution and lifetime of the volcanic aerosols, their basic microphysical structures (e.g.. size distribution, concentration, mass ratio, and surface area) and radiative properties. The persistent volcanic aerosols can produce significant anomalies in the radiation field, which have important climatic consequences. The large enhancement in aerosol surface area can result in measurable global stratospheric ozone depletion.
\end{abstract}

\section{Introduction}

Following major volcanic eruptions, the stratospheric aerosol layer, known as the Junge layer [Junge et al.. 1961] was greatly enhanced by particles created from the sulfurbearing gas (such as $\mathrm{SO}_{2}$ ) emissions as well as ash particles [Farlow et al., 1981; Turco et al., 1982; Hofmann and Rosen, 1983, 1984, 1987; Deshler et al. 1992; Sheridan et al., 19921. The significant enhancement of the stratospheric aerosol layer can exert an extra forcing on the global climate system by altering the radiation balance and can also influence heterogeneous chemical reactions and thus global ozone abundance. To fully understand the atmospheric effect of volcanic eruption, one needs to clarify the chemical and physical mechanisms of the formation, evolution, and persistence of volcanic clouds in the stratosphere. The observational and modeling studies of volcanic clouds formed in the stratosphere following major eruptions in the past two decades thus have been greatly expanded, particularly, due

Copyright 1995 by the American Geophysical Union.

Paper number 94JD03325.

0148-0227/95/94JD-03325\$05.00 to the recent occurrence of several major eruptions such as Mount St. Helens in 1980. El Chichón in 1982. and Mount Pinatubo in 1991: however. only a few of model calculations to date can compare directly with observations of aerosol properties of volcanic clouds in details. This study is to develop a volcanic aerosol model based on Turco Toon's tracer model to study volcanic aerosols produced by the Pinatubo eruption and compare our model results directly with observational data collected following the event.

The eruption of Pinatubo $\left(15^{\circ} \mathrm{N}, 120^{\circ} \mathrm{E}\right)$ on June 15.1991 . resulted in the most massive stratospheric sulfate cloud in this century and provided a unique nature laboratory for volcanic aerosol studies. The measurements following the Mount Pinatubo eruption have supplied large and diverse sets of observations. The eruption columns over the vent reached in excess of $35 \mathrm{~km}$ [Woods and Self. 1992], and the densest clouds were initially located between 20 and $30 \mathrm{~km}$ in tropical regions [Mc Cormick und Veiga, 1992: Deshler et al., 1992; Jäger, 1992]. Total ozone mapping spectrometer (TOMS) and stratospheric aerosol and gas experiment (SAGE) II satellite sensors monitored the distributions of $\mathrm{SO}_{2}$ amounts and aerosol optical depths, respectively $[B$ luth 
et al., 1992; McCormick and Veiga, 1992]. The satellite data show that the cloud dispersed westward in the easterly phase of the quasi-biennial oscillation (QBO) of the stratospheric circulation and encircled the Earth within 3 weeks. Its meridional dispersion was relatively slow, and the cloud remained in a tropical belt extending from about $20^{\circ} \mathrm{S}$ to $30^{\circ} \mathrm{N}$ for the first few months after the eruption.

TOMS data also show that about $20 \mathrm{Mt}$ of $\mathrm{SO}_{2}$ was injected into the stratosphere, which is about 3 times the amount produced by the $1982 \mathrm{El}$ Chichón eruption [Bluth et al., 1992]. This large emission of $\mathrm{SO}_{2}$ provided the source for sulfuric acid particles in the Pinatubo cloud. Measurements of the aged Pinatubo aerosols indicate that $99 \%$ were pure $\mathrm{H}_{2} \mathrm{SO}_{4} / \mathrm{H}_{2} \mathrm{O}$ solution droplets, confirming the importance of homogeneous nucleation of gas-to-particle conversion as a volcanic aerosol formation mechanism [Deshler et al., 1992; Sheridan et al., 1992]. The observed size distributions of the volcanic aerosols in the stratosphere exhibit multiple modes [Deshler et al., 1992; Pueschel et al., 1992]. Measured modal sizes of sulfate particles generated in situ from gaseous $\mathrm{SO}_{2}$ by aircraft and balloon samples, and lidar and satellite observations are around 0.3 -0.6 $\mu \mathrm{m}$ [Pueschel et al., 1992; Deshler et al., 1992; Russell et al., 1993b; M. J. Post and C. J. Grund, Lidar observations of atmospheric processes involving volcanic clouds, preprint, 1993]. Observed stratospheric aerosol extinction from SAGE II multiwavelength measurements clearly show the significant difference in size and mass between the background and volcanic aerosols following the Pinatubo eruption [Thomason, 1992]. Optical depths of several tenths $(0.2-0.5)$ were observed in Pinatubo eruption clouds during the first few months [McCormick and Veiga, 1992; Stowe et al., 1992; Valero and Pilewskie, 1992; Pueschel et al., 1992], which were even larger than those of the El Chichón eruption. Such values for the optical depth exceed the ambient values by more than 1 order of magnitude.

Several detailed model simulations of volcanic clouds have been carried out in the last two decades. Turco et al. [1983] studied the chemical and physical properties and evolution of the stratospheric clouds produced by the eruption of Mount St. Helens using a one-dimensional (1-D) model. They concluded that the general microphysical behavior and structure of the clouds could be adequately reproduced with a 1-D model. However, because the sulfur chemistry at the time did not involve the fast reaction of $\mathrm{HSO}_{3}$ with $\mathrm{O}_{2}$, a heterogeneous chemical conversion mechanism of $\mathrm{SO}_{2}$ into sulfate was needed to explain the rapid buildup of sulfate mass following the exuption. Pinto et al. [1989] used basically the same moded but with updated chemistry to examine the effects of stratospheric volcanic clouds generated by very large eruptions. They suggested that the physical and chemical impacts of volcanic aerosols must be self-limiting due to the highly monlinear growth and coagulation processes leading to larger-sized volcanic aerosols with short lifetimes against sedimentation. Turco [1990] simulated the El Chichón eruption claod with a 1-D model and found that homogeneous nucleation was significant in the core of the volcanic eruption; actosol concentrations were dominated by newly formed particles.

Cadle et al. [1976, 1977] and Cadle [1980] simulated the global dispersion of several specific volcanic clouds using a two-dimensional (2-D) meridional circulation model. Capone et al. [1983] developed a 2-D model based upon the earlier work of Turco et al. [1979a, b] and Toon et al. [1979a, b] to study the El Chichón volcanic clouds. These simulations reproduced lidar and satellite observations well but inaccurately depicted the rate of meridional dispersion of the clouds. Recently, Tie et al. [1994] simulated El Chichón aerosols using a coupled 2-D dynamical/chemical/microphysical model; the resultant aerosol properties are comparable to that observed following the El Chichón eruption. Meanwhile, Bekki and Pyle [1994] also incorporated the sulfate microphysics into 2-D chemistry/dynamical model to simulate Pinatubo aerosols. They found significant discrepancies between model simulations and observation in the timing of aerosol loading peak and in the magnitude of the surface area due to the absence of homogeneous nucleation in their model. Some other multi-dimensional modeling efforts have been limited to studies of dynamical transport of volcanic clouds or the effects of volcanic clouds on atmospheric circulation and composition [Boville et al.. 1991: Brasseur and Granier, 1992: Pitari, 1993: Young et al., 1994].

We use a 1-D model to study the Pinatubo clouds with emphasis on understanding the chemical and microphysical mechanisms involved in aerosol formation and evolution. and on simulations of aerosol microstructure and radiative properties. Our model includes gas-phase sulfur photochemistry, gas-to-particle conversion of sulfur, and aerosol microphysics. The dynamical transport of the volcanic eruption cloud is parameterized as horizontal dilution and vertical diffusion. With updated emission data from Pinatubo eruptions. we use the I-D model to reproduce the observed properties of the volcanic clouds.

\section{Model Description}

We incorporated the basic chemical and physical processes discussed by Turco et al. [1979a. b] with updated chemical reactions, and most of numerical algorithms developed by Toon et al. [1988], to build up a sophisticated sulfate aerosol model for stratospheric conditions. The major components of this model and their interactions through chemical and physical processes are illustrated in Figure 1. The primary source of the undisturbed stratospheric ulfur is OCS which gets into the stratosphere mainly through dynamical diffusion processes from the troposphere [Crutzen. 1976]. It is then decomposed to produce gas phase $\mathrm{H}_{2} \mathrm{SO}_{4}$ through a number of photochemical reactions (see Table 1 ). During volcanic eruptions, a large amount of sulfur dioxide is directly injected into the stratosphere and converted into $\mathrm{H}_{2} \mathrm{SO}_{4}$ by $\mathrm{OH}$ oxidation. Then. $\mathrm{H}_{2} \mathrm{SO}_{4}$ vapor interacts with stratospheric aerosols through nucleation. condensational growth, and evaporation. Three types of aerosol are considered in the model, namely. pure involatile particles (Aitken particles from troposphere or ash grains injected by volcanic eruption), pure volatile $\left(\mathrm{H}_{2} \mathrm{SO}_{4} / \mathrm{H}_{2} \mathrm{O}\right)$ droplets and mixed aerosols which have cores of the first type and shells of $\mathrm{H}_{2} \mathrm{SO}_{4} / \mathrm{H}_{2} \mathrm{O}$ solution around the cores. The particles of the first type are largely transported from the troposphere under nonvolcanic conditions but are strongly disturbed by volcanic ash particles. Pure sulfuric acid particles in the second type result only from binary homogeneous nucleation. The mixed aerosols result from binary heterogeneous nucleation of the solid particles of the first type or from coagulation between the other two types of aerosols. Depending on the 


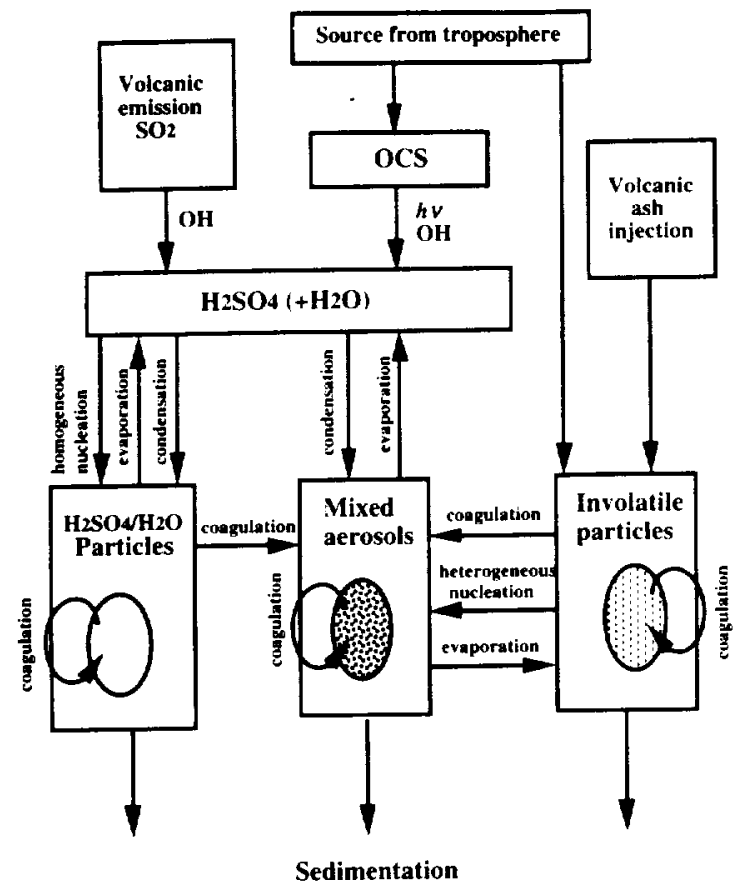

Figure 1. A schematic diagram of the chemical and microphysical processes treated in our stratospheric sulfate aerosol model.

supersaturation of $\mathrm{H}_{2} \mathrm{SO}_{4}$ vapor, the mixed and the pure sulfuric acid particles can expand through condensation or shrink due to evaporation. If a mixed aerosol is completely evaporated, then its core is released and returned to the first type of aerosol. Self coagulation for each type of aerosol and heterogeneous coagulation among different types are all included in the model. Gravitational sedimentation is also treated in the model for each kind of aerosol, serving as a major sink for the total aerosol mass. Such sedimentation alters the size distribution as larger ash particles fall out.

Under normal conditions in the stratosphere, homogeneous nucleation may not be a dominant source of new particles: however, it becomes extremely important in volcanic clouds because high concentrations of $\mathrm{SO}_{2}$ can significantly increase the production of sulfuric acid vapor and thus acid supersaturation. Once substantial homogeneous nucleation happens, a large number of very fine pure $\mathrm{H}_{2} \mathrm{SO}_{4}$ ' $\mathrm{H}_{2} \mathrm{O}$ droplets will be produced within a short time. These newly formed particles then grow quickly to form the spectrum of the pure acid aerosols or obtain cores by coagulating with other two types to transform to the third type of aerosols. Our model is specially suitable for studying the rapid formation of new particles as in a volcanic plume because a new efficient heteromolecular homogeneous and heterogeneous nucleation scheme [Zhao, 1993] is implemented.

Throughout this study, a physical height coordinate is used for $1-\mathrm{D}$ simulations with $2-\mathrm{km}$ vertical resolution and 30 layers from ground to $60 \mathrm{~km}$. Implicit numerical scheme and family technique with three families (e.g., $F_{1}=$ OCS, $F_{2}=$ $\mathrm{S}, \mathrm{SO}, \mathrm{SO}_{2}$, and $F_{3}=\mathrm{SO}_{3}, \mathrm{HSO}_{3}, \mathrm{H}_{2} \mathrm{SO}_{4}$ ) are used to solve chemical tracers. The vertical profiles of $\mathrm{O}$ and $\mathrm{H}_{2} \mathrm{O}$ concentrations are fixed in accordance with photochemical model predictions by Brasseur and Solomon. OH concentrations are estimated from $\mathrm{SO}_{2}$ data collected in volcanic clouds following the Pinatubo eruption (see next section). All the chemical reaction rates are taken from standard compilations [DeMore et al.. 1991]. Aerosols are different from gas tracers because the size distribution must be resolved, yielding another physical dimension and additional complexity. In order to cover the wide range of aerosol sizes with a fair resolution. we specified the size bins by doubling particle volume from one category to the next. resulting in about 10 volume intervals per decade of size: 40 size bins cover the particle radius range from about 0.001 to $10 \mu \mathrm{m}$ in the current version of the model. The details of the basic formulation and computational algorithms of the model are given by Turco et al. [1979a, b], Toon et al. [1979a, b]. Toon et al. [1988], and Zhas [1993].

\section{Model Physical Setting}

To simulate the Mount Pinatubo volcanic cloud. we generated a background aerosol field in the tropical region.

Table 1. Photochemical Reactions of Sulfur Components in the Stratosphere

\begin{tabular}{|c|c|c|}
\hline & Reaction & Rate \\
\hline$R^{\prime}$ & $\mathrm{S}+\mathrm{O}_{2} \stackrel{\hat{k}_{1}}{\rightarrow} \mathrm{SO}+\mathrm{O}$ & $k_{1}=2.3 \times 10^{-12}$ \\
\hline$R^{2}$ & $\mathrm{SO}+\mathrm{O}_{2} \stackrel{k_{2}}{\rightarrow} \mathrm{SO}_{2}+\mathrm{O}$ & $k_{2}=2.6 \times 10^{-13} \mathrm{e}^{-2+100 /}$ \\
\hline$R^{3}$ & $\mathrm{SO}_{2}+\mathrm{OH}+\mathrm{M} \stackrel{k}{\rightarrow} \mathrm{HSO}_{3}+\mathrm{M}$ & $\begin{array}{l}k_{0}^{300}=3.0 \times 10^{-31}, n=3.3 * \\
k_{x}^{300}=1.5 \times 10^{-12}, m=0^{*}\end{array}$ \\
\hline$R^{4}$ & $\mathrm{HSO}_{3}+\mathrm{O}_{2} \stackrel{k_{4}}{\rightarrow} \mathrm{SO}_{3}+\mathrm{HO}_{2}$ & $k_{4}=1.3 \times 10^{-12} e^{-3301}$ \\
\hline$R^{5}$ & $\mathrm{SO}_{3}+\mathrm{H}_{2} \mathrm{O} \stackrel{k}{\rightarrow} \mathrm{H}_{2} \mathrm{SO}_{4}$ & $k_{s}=6.0 \times 10^{-15}$ \\
\hline$R^{6}$ & $\mathrm{OCS}+\mathrm{O} \stackrel{k_{6}}{\rightarrow} \mathrm{SO}+\mathrm{CO}$ & $k_{\mathrm{h}}=2.1 \times 10^{-11} e^{-22001}$ \\
\hline$J^{1}$ & $\mathrm{OCS}+h v \stackrel{J_{1}}{\rightarrow} \mathrm{S}+\mathrm{CO} . \quad \lambda<288 \mathrm{~nm}$ & \\
\hline$J^{2}$ & $\mathrm{SO}_{2}+h \nu \stackrel{J_{2}}{\rightarrow} \mathrm{SO}+\mathrm{O}, \quad \lambda<220 \mathrm{~nm}$ & \\
\hline
\end{tabular}




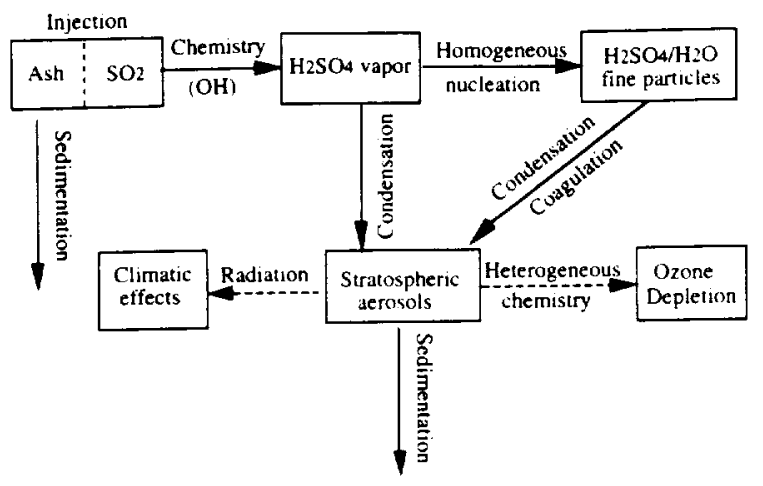

Figure 2. Flow diagram of the volcanic aerosol model. The potential effects of volcanic aerosols on global climate and stratospheric ozone depletion indicated with dashed line arrows are not included in the current model.

setting the tropopause height at $15 \mathrm{~km}$. We ran the model until it reached a steady state and took the ambient aerosol spatial concentration distributions in this state as an initial value for the volcanic cloud simulations to which the volcanic sources of $\mathrm{SO}_{2}$ gas and ash particles are added. The estimate of total $\mathrm{SO}_{2}$ injection from the TOMS measurements is about $20 \mathrm{Mt}$ from the Pinatubo eruption. Observations of ash particles and their size distribution in the initial volcanic plume are very rare. For model simulations, we put $20 \mathrm{Mt}$ of $\mathrm{SO}_{2}$ and $100 \mathrm{Mt}$ of volcanic ash into the model stratosphere uniformly distributed between 20 and $30 \mathrm{~km}$. Because of absence of observations, the size distribution of ash particles used here is assumed similar to that in an earlier study by Turco et al. [1983], e.g., a bimodal lognormal size distribution for the silicates with $97.5 \%$ of the mass in a mode at $r=3 \mu \mathrm{m}$ with $\sigma=0.8$, and $2.5 \%$ of the mass in a mode at $r=0.5 \mu \mathrm{m}$ with $\sigma=0.5$.

The flow diagram (Figure 2) shows the basic characteristics of the volcanic aerosol model. After the eruption, the large silicate particles quickly fall out off the stratosphere by gravitational sedimentation, while the $\mathrm{SO}_{2}$ from the volcanic injection is transformed into $\mathrm{H}_{2} \mathrm{SO}_{4}$ by photochemical processes. $\mathrm{H}_{2} \mathrm{SO}_{4}$ concentrations can be greatly increased over ambient. Once the supersaturation of $\mathrm{H}_{2} \mathrm{SO}_{4}$ vapor exceeds the critical value for homogeneous nucleation, a large number of $\mathrm{H}_{2} \mathrm{SO}_{4} / \mathrm{H}_{2} \mathrm{O}$ solution droplets will be formed by heteromolecular homogeneous nucleation. The newly formed aerosols can grow rapidly to measurable size because of efficient condensation and coagulation and dominate the volcanic clouds shortly after the eruption. They can stay in the stratosphere for several years owing to their relatively small size and can travel globally with the atmospheric circulation, thereby playing a potential role in blocking atmospheric radiation and in catalyzing global ozone depletion.

The chemical oxidation of $\mathrm{SO}_{2}$ into $\mathrm{H}_{2} \mathrm{SO}_{4}$ is crucial for aerosol formation and evolution. The conversion rate is mainly controlled by $\mathrm{OH}$ concentration. Very limited direct measurements of $\mathrm{OH}$ concentrations have ever been made in volcanic clouds. Read et al. [1993] crudely estimated $\mathrm{OH}$ concentrations as $1.2 \sim 3.3 \times 10^{6} \mathrm{~cm}^{-3}$ between 21 and 26 $\mathrm{km}$ in the Pinatubo cloud, using the observed decay rate of $\mathrm{SO}_{2}$. To reasonably estimate the $\mathrm{OH}$ concentrations and thus the conversion rates of $\mathrm{SO}_{2}$ in the Pinatubo cloud, we ran the chemistry model for different $\mathrm{OH}$ concentrations and fit the model outputs with observations. Figure $3 \mathrm{a}$ indicates the changes in total $\mathrm{SO}_{2}$ mass with time, associated with three different levels of $\mathrm{OH}$ (Figure 3b). Comparing the model results (curves) with the data (scattering symbols) observed by TOMS [Bluth et al., 1992], aircraft [Mankin et al., 1992], solar backscattered ultraviolet (SBUV) [MCPeters, 1992], and MLS [Read et al., 1993], we found that the model prediction with an $\mathrm{OH}$ concentration of $2 \times 10^{6}$ $\mathrm{cm}^{-3}$ below $30 \mathrm{~km}$ generally agrees well with the data collected from different sources during the first 5 months. The predicted total $\mathrm{SO}_{2}$ mass with this $\mathrm{OH}$ level appears slightly higher than the MLS measurements after about 150 days. The inconsistency may result from the fact that $\mathrm{SO}_{2}$ mass had fallen below the uncertainty level of MLS measurement after that time. Thus we use $2 \times 10^{6} \mathrm{~cm}^{-3}$ of $\mathrm{OH}$ concentration in the simulation of Pinatubo volcanic aerosols.

The dynamical processes in this 1-D model are parameterized as vertical diffusion and horizontal dilution. We use a vertical profile of diffusion coefficients similar to that used by Turco [1979a, b]. The horizontal dispersion of volcanic cloud was simply treated using a cloud area expansion function. According to observations [Bluth et al., 1992; Mc Cormick and Veiga, 1992; Stowe et al., 1992], Pinatubo volcanic plumes initially propagated zonally and encircled the Earth
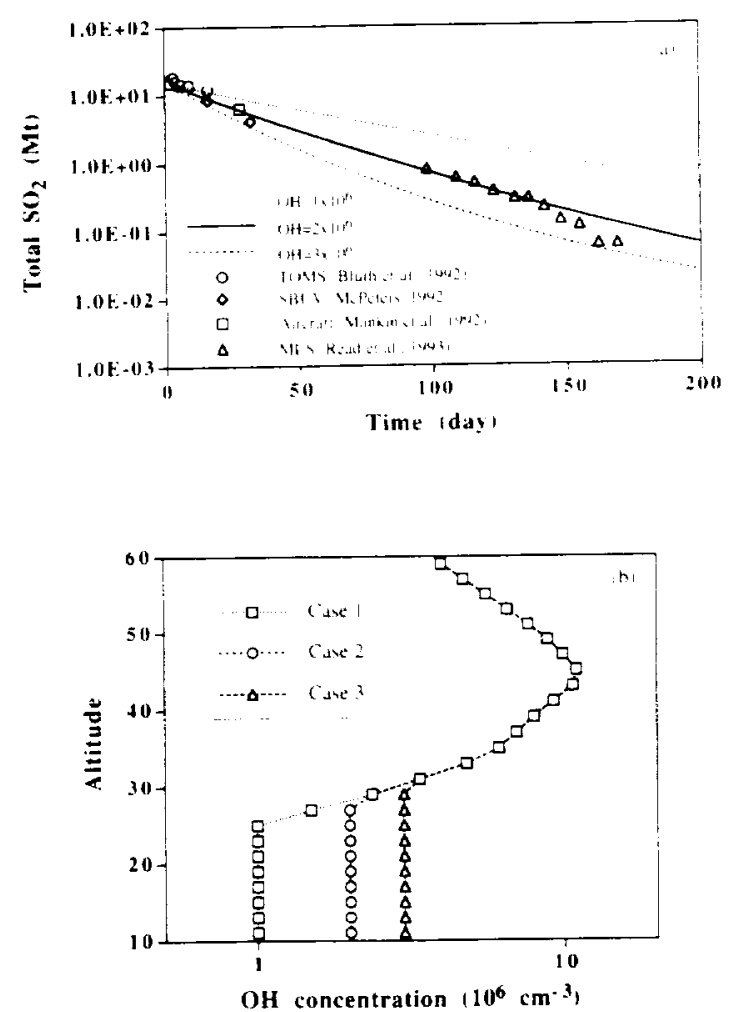

Figure 3. (a) Changes of total $\mathrm{SO}_{2}$ masses versus time in volcanic clouds; model calculations (curves) associated with three different $\mathrm{OH}$ profiles as shown in Figure $3 b$ and observations (symbols) collected from aircraft and satellite following the eruption of Mount Pinatubo. (b) The three $\mathrm{OH}$ profiles used in calculations for Figure $3 a$. Read $1.0 \mathrm{E}+02$ as $1.0 \times 10^{2}$. 
within a month. The meridional dispersion is relatively slow and it took a year or so to cover the whole globe. For simplicity, we assumed that the cloud area expands with time as shown in Figure 4, maintaining a uniformly mixed composition horizontally. The concentration of each species in the cloud at any level is diluted as ambient air is entrained. The rates of the dilution of cloud materials are determined by the rates of horizontal spreading of the cloud. By considering two separate periods, the expansion of cloud area in Figure 4 is expressed as

$$
\begin{gathered}
A(t)=A_{0}+K_{1}\left(t-t_{0}\right), \text { when } t_{0} \leq t \leq t_{1} \\
A(t)=A_{1}+K_{2}\left(t-t_{1}\right), \text { when } t_{1} \leq t \leq t_{2} \\
A(t)=A_{a}, \text { when } t \geq t_{2} .
\end{gathered}
$$

$A$ denotes the cloud cover area $\left(\mathrm{cm}^{2}\right), K_{1}$ is the initial horizontal diffusion coefficient $\left(\mathrm{cm}^{2} / \mathrm{s}\right)$, which can be determined from the observed spreading speed of the volcanic cloud. Also $t$ is time, and $t_{0}$ is the initial time of the model $\left(t_{0}=0\right)$, corresponding to the initial cross section $A_{0}=10^{7}$ $\mathrm{km}^{2}$ of the volcanic plume. $A_{1}$ denotes the cloud area at time $t_{1}$ and $A_{a} \approx 51 A_{0}$ is the total Earth area. After the eruption, the volcanic cloud encircles the Earth in about a month and covers about $1 / 3$ of the surface, then disperses poleward and covers the globe in about a year. With this kind of cloud expansion rate we can easily obtain $K_{1}=0.5 \mathrm{~A}_{0} /$ day and $K_{2}=0.1 \mathrm{~A}_{0} /$ day by setting $t_{1}=30$ days and $t_{2}=365$ days. We have neglected the differences in spreading rates at different altitudes actually associated with the dynamics of the stratosphere.

\section{Numerical Simulations}

Using optical particle counter measurements, Hofmann and Rosen [1983] studied sulfuric acid droplet formation and growth in the stratosphere from the 1982 eruption of $\mathrm{El}$ Chichón. They suggested two important mechanisms for particle formation. One is that sulfate droplets are formed by homogeneous nucleation from the gas phase due to enhanced $\mathrm{H}_{2} \mathrm{SO}_{4}$ vapor derived from $\mathrm{SO}_{2}$ injection. The other is the rapid growth of the existing particles. Pinto et al. [1989] conducted numerical experiments with 1-D aerosol microphysical and photochemical models. They confirmed the importance of the second view and concluded that aerosol microphysical processes of condensation and coagulation act to produce larger particles and limit the total number of particles as the $\mathrm{SO}_{2}$ injection rate is increased. However, the importance of homogeneous nucleation for volcanic aerosol formation, as indicated by observations of pure sulfate particles in volcanic clouds, has never been carefully quantified. Numerical simulations carried out here provide a consistent and detailed look at aerosol formation and evolution in a well-characterized stratospheric volcanic cloud.

\section{$\mathrm{H}_{2} \mathrm{SO}_{4}$ Vapor}

With the physical setting described previously, we integrate the model for 1000 days. The vertical profiles and time series of the simulated $\mathrm{H}_{2} \mathrm{SO}_{4}$ are shown in Figure 5 . $\mathrm{H}_{2} \mathrm{SO}_{4}$, resulting from the conversion of high initial $\mathrm{SO}_{2}$ concentrations in the volcanic cloud, build up very quickly to levels sufficient for homogeneous nucleation to occur. For

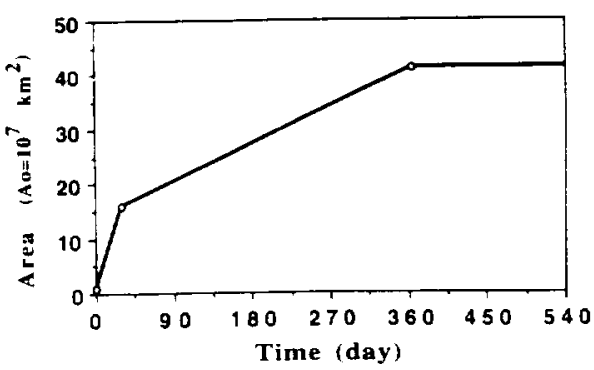

Figure 4. Volcanic cloud area expansion adopted in the $1-\mathrm{D}$ volcanic model. We assume that the initial plume cross area is $A_{0}=10^{7} \mathrm{~km}^{2}$.

instance, $\mathrm{H}_{2} \mathrm{SO}_{4}$ mixing ratios exceed 0.05 parts per billion by volume (ppbv) between 20 and $30 \mathrm{~km}$ during the first few days after the eruption, more than 3 orders of magnitude higher than ambient $\mathrm{H}_{2} \mathrm{SO}_{4}$ levels. About the same order of $\mathrm{H}_{2} \mathrm{SO}_{4}$ mixing ratio was estimated by Hofmann and Rosen [1983] in El Chichón's eruption plume. The model simulation also shows that such high concentrations of $\mathrm{H}_{2} \mathrm{SO}_{4}$ vapor cannot be maintained for a long period of time because $\mathrm{H}_{2} \mathrm{SO}_{4}$ vapor is quickly converted to particles by efficient condensation onto preexisting particles, volcanic ash grains, and freshly nucleated particles.

$\mathrm{H}_{2} \mathrm{SO}_{4}$ vapor concentrations are determined by production from chemical reactions and loss to particles through nucleation and condensation. The time constant for chemical production of $\mathrm{H}_{2} \mathrm{SO}_{4}$ is equivalent to the $\mathrm{SO}_{2}$ oxidation time, about 30 days, which is much longer than the time constant for the loss of $\mathrm{H}_{2} \mathrm{SO}_{4}$ vapor to aerosols. Hofmann and Rosen [1983], using optical counter measurements at 25 $\mathrm{km}$, inferred an "e-folding" time constant of about 15-20 min for $\mathrm{H}_{2} \mathrm{SO}_{4}$ loss to particles in the El Chichón cloud. The preeruption average aerosol distribution at $25 \mathrm{~km}$ has a surface area sufficient to absorb $\mathrm{H}_{2} \mathrm{SO}_{4}$ vapor in about 8 hours, still substantially faster than $\mathrm{SO}_{2}$ oxidation. The time constant for nucleation is even much smaller than that of condensational growth. Therefore although there is continuous conversion of the volcanic emissions of $\mathrm{SO}_{2}$ into $\mathrm{H}_{2} \mathrm{SO}_{4}$, the acid vapor can not accumulate to high concentrations. Rather, it is almost immediately converted to particles. The conversion rates are subsequently controlled by the rates of transformation of $\mathrm{SO}_{2}$ into $\mathrm{H}_{2} \mathrm{SO}_{4}$ (e.g.. OH concentrations).

The $\mathrm{H}_{2} \mathrm{SO}_{4}$ concentrations in the stratosphere can be even lower than their ambient levels about 1 year after the eruption. This situation occurs because the production of $\mathrm{H}_{2} \mathrm{SO}_{4}$ almost returns to the background rate while the volcanic aerosol surface area remains enhanced in the low stratosphere, creating a greater then normal sink for $\mathrm{H}_{2} \mathrm{SO}_{4}$ vapor. Lower $\mathrm{H}_{2} \mathrm{SO}_{4}$ concentrations, in turn, slow particle growth.

\section{Aerosol Size Distribution}

The simulated aerosol number size distributions (Figure 6) show that volcanic aerosols are distinct from background particles in both concentration and size spectrum. The aerosol concentrations are greatly enhanced and the size distributions exhibit multiple modes. One of the most significant changes is the appearance of very small particles with 

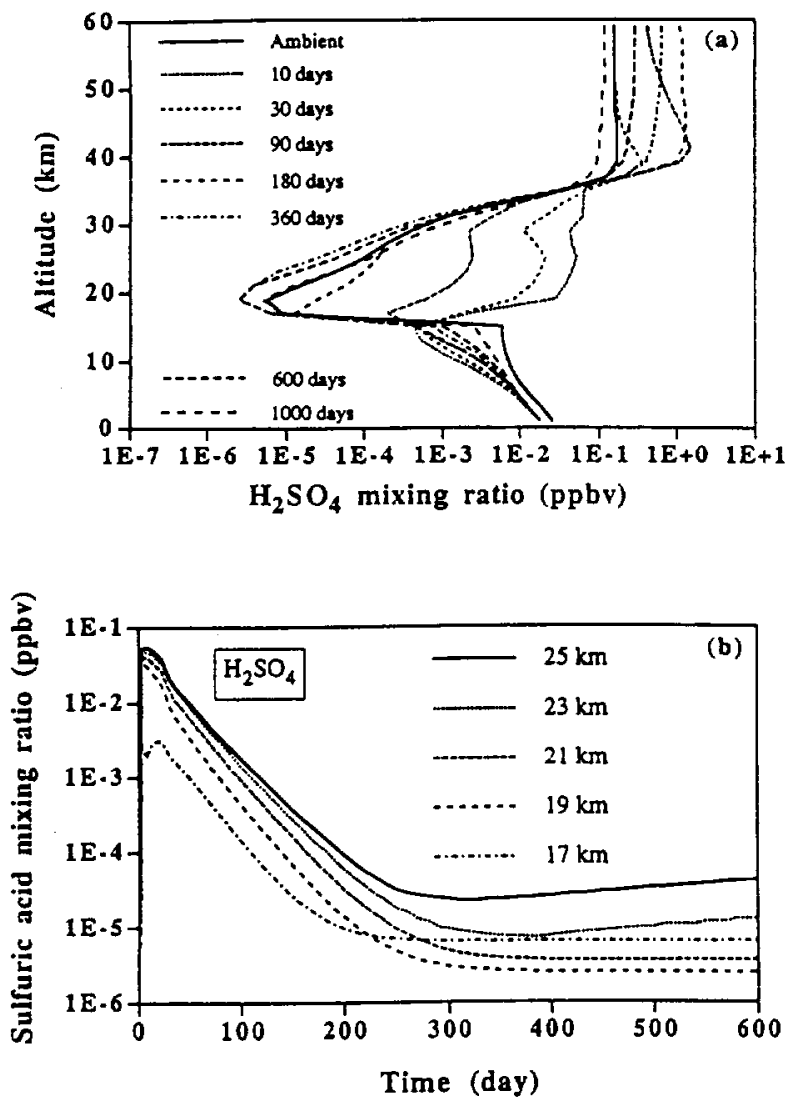

Figure 5. Simulated evolution of $\mathrm{H}_{2} \mathrm{SO}_{4}$ mixing ratio (ppbv) following the Mount Pinatubo eruption. (a) Vertical profiles at different times; (b) time series at different altitudes. Read IE -7 as $1 \times 10^{-7}$.

the smallest sizes near $10^{-3} \mu \mathrm{m}$. The number concentrations of these small droplets can exceed $10^{5} \mathrm{~cm}^{-3}$ near $21 \mathrm{~km}$. Obviously, the high number concentrations of small droplets are created in situ through binary homogeneous nucleation that is stimulated by high $\mathrm{H}_{2} \mathrm{SO}_{4}$ concentration. These newly formed aerosols grow rapidly by condensation while their number concentrations are reduced significantly by coagulation. By 10 days after the eruption, the peak radius in number size distribution has been close to $0.1 \mu \mathrm{m}$ already, with number concentrations of a few hundreds $\mathrm{cm}^{-3}$. After about 1 month following the eruption, new particle formation by homogenous nucleation almost ceases when enough sulfate mass (and surface area) has been generated to consume acid vapor effectively by condensation, and thus to reduce the supersaturation below its critical value for binary homogenous nucleation. Condensational growth and coagulation then continue to finalize the spectrum of residual volcanic sulfate aerosols. After 3 months, less than $50 \mathrm{~cm}^{-3}$ are left and the condensational growth of these sulfates becomes slow due to the reduction of acid vapor concentration; aerosol size thus is stabilized at around $0.4 \mu \mathrm{m}$.

Another distinct feature is the volcanic dust initially pumped into the stratosphere with peaks near $0.5 \mu \mathrm{m}$ and 3 $\mu \mathrm{m}$. These large ash particles as shown in the figure fall out very quickly and most of them disappear after a few months. Along with newly formed sulfate droplets, ash grains and preexisting ambient particles, which can be heterogeneously nucleated by the $\mathrm{H}_{2} \mathrm{SO}_{4} / \mathrm{H}_{2} \mathrm{O}$ vapors, also grow by condensation. Thus a substantial amount of sulfur vapor is transformed to particles within the first few hours and days, whereas the conversion rate of $\mathrm{SO}_{2}$ to $\mathrm{H}_{2} \mathrm{SO}_{4}$ does not increase. Therefore the production of sulfate mass is limited by the chemical conversion rate of $\mathrm{SO}_{2}$.

The mass size distributions (Figure 7) also delineate three distinct volcanic aerosol modes. The mode at the smallest sizes is composed of newly formed sulfuric acid/water droplets. The other two modes both represent ash particles, which initially dominate the total aerosol mass in the stratosphere, but which settle out after about a month. The ambient particle mass is too low to be seen on the plots of 25 and $21 \mathrm{~km}$. The sulfate mode increases in size due to condensation and coagulation processes and becomes the dominant fraction of the total aerosol mass after ash grains fall out. The sulfate mass increases during the first few months when condensational growth is significant and then decreases when condensational growth becomes slow and sedimentation is a dominant sink of aerosol mass.

The volcanic sulfate aerosols can stay in the stratosphere up to several years and significantly alter the nature of the Junge layer. The aerosol number and mass size distributions after more than 2 years following the eruption show that volcanic aerosols are still dominant in the lower stratosphere although the background aerosols are recovering. In the upper troposphere, the volcanic cloud also significantly enhances aerosol mass although it has a minor contribution to the aerosol concentrations (see the plots of $15 \mathrm{~km}$ ). Some large-sized particles are added into the troposphere by sedimentation from the stratosphere, and changes in mass size distribution are obvious.

The number size distributions, after most ash grains fall out, are sharply limited near $1 \mu \mathrm{m}$ in the stratosphere. The stabilized mode radii in number size distributions are close to that in mass size distributions, around $0.4 \mu \mathrm{m}$. This value is close to the observed $0.3 \sim 0.5 \mu \mathrm{m}$ "effective" radius (e.g.. the third moment of size spectrum divided by the second moment) deduced from advanced very high resolution radiometer (AVHRR) satellite data and aircraft sampling following the Pinatubo eruption [Russell et al. 1993a, b; Pueschel et al., 1992]. Figures 8a and $8 \mathrm{~b}$ show the time series of simulated effective radii of total aerosols and pure sulfates, respectively. The high initial values of effective radii for total aerosols result from large ash particles and decrease sharply as the ash grain fall off during the first few weeks. After then, the effective radii increase because of the efficient growth of new sulfate droplets as shown clearly in Figure 8b. The maximum values generally appear around one-half year when the condensation growth becomes insignificant.

Comparing Figures $8 \mathrm{a}$ and $8 \mathrm{~b}$, we find that the effective radii of total aerosols are larger than those of sulfates, especially in lower stratosphere during the first 2 years, which implies that considerable amount of mass for mixed aerosols, sulfates but with ambient or ash particles as cores. are still present in the lower stratosphere. However, 2 years after the eruption, the situation is opposite. The radii of sulfates decrease slower and have larger values than those for total aerosols because the larger mixed particles are removed by sedimentation, and small Aitken particles are transported into the stratosphere by vertical diffusion, whereas the sulfates have moderated sizes and do not show a significant change in effective radius. 

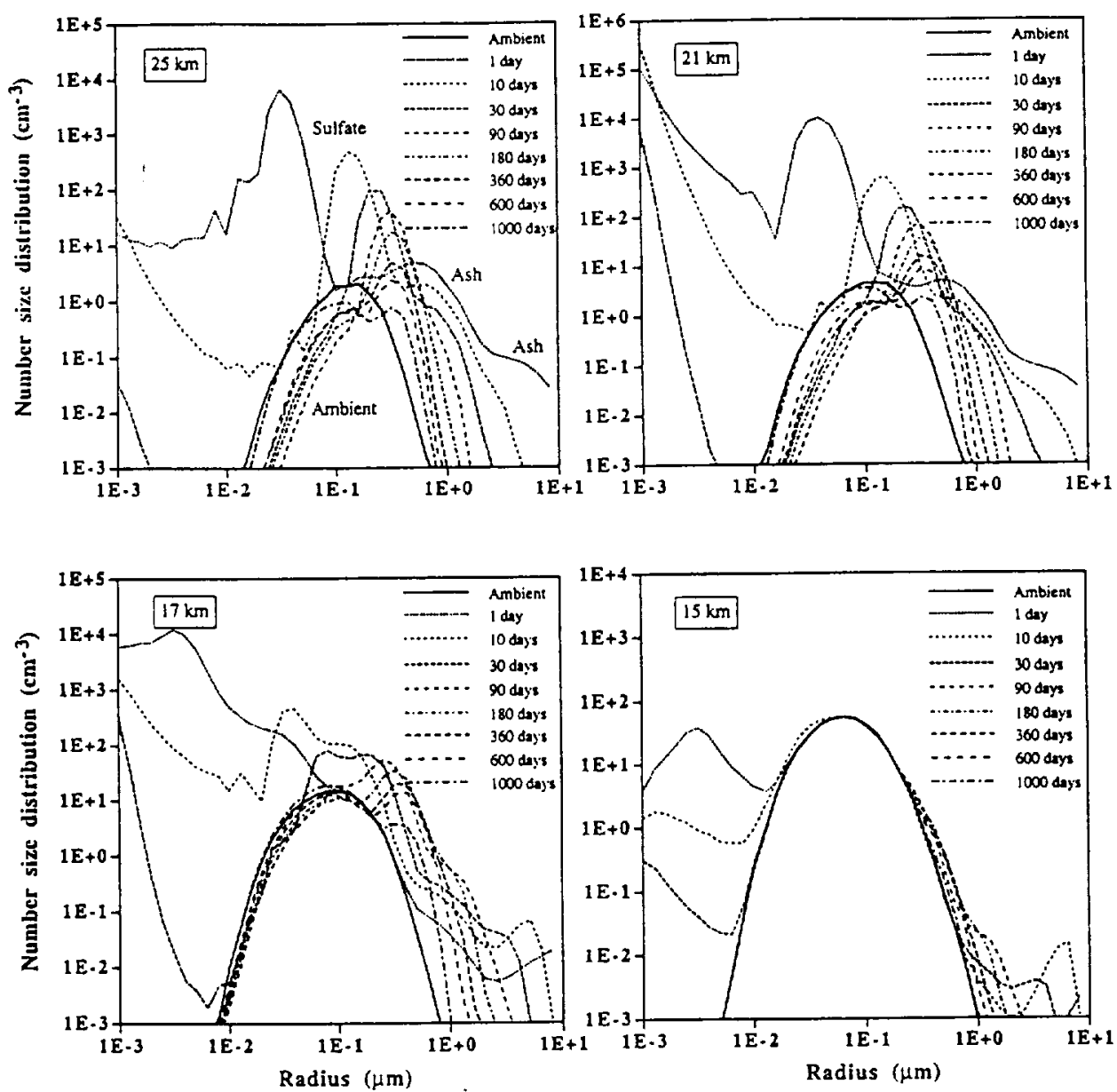

Figure 6. Aerosol number size distributions simulated in the Pinatubo eruption cloud with a onedimensional model. Read $1 E+5$ as $1 \times 10^{5}$.

From Figure $8 b$ we note that there are different aerosol growth rates at different altitudes. For example, the effective radius reaches its maximum values around one-half year after eruption at $25 \mathrm{~km}$, whereas the maximum appears over a year at $19 \mathrm{~km}$. One-dimensional model simulations of volcanic clouds carried out by Pinto et al. [1989] indicated that the maximum radius for the case with $10 \mathrm{Mt}$ of $\mathrm{SO}_{2}$ injection appeared about 1 year with its value of $0.4 \mu \mathrm{m}$. Aircraft measurements also show a similar feature but with a slightly larger value of aerosol size, which was probably affected by the eruptions of Mount Spurr in Alaska in 1992 [Goodman et al., 1994]. Hofmann and Rosen [1983] observed that aerosol growth in the El Chichon volcanic clouds ceased after 7 months. Although the 1-D model results cannot be directly compared with observations collected from different locations and altitudes, the model simulations of the Pinatubo volcanic aerosols are generally reasonable and consistent with these earlier modelings and observations.

\section{Vertical Distribution}

The vertical profiles of aerosol concentrations for radii greater than $0.15 \mu \mathrm{m}$ (Figure 9a) show that the Pinatubo volcanic eruption greatly enhanced the background aerosols in the entire region from the tropopause to about $35 \mathrm{~km}$. The densest aerosol cloud is near $20 \mathrm{~km}$ with peak concentration over $100 \mathrm{~cm}^{-3}$ within the first few weeks. By about 2 years, the aerosol concentration is still significant above its ambient value, and the peak altitude is down to $17 \mathrm{~km}$, close to the tropopause. The aerosol concentration does not completely return to its background level until after 3 years. The vertical profiles of aerosol concentration for radii greater than 0.25 $\mu \mathrm{m}$ (Figure 9b) show some different features. The peak concentration at 10 days is lower than that at 30 days. Obviously, most large particles must be ash grains at 10 days. By nearly 30 days after the eruption, the newly formed, initially small sulfates grow to sizes larger than 0.25 $\mu \mathrm{m}$ and dominate the aerosol concentration after that. Compared with Figure $9 \mathrm{a}$, more than 50 percent of the sulfates have grown larger than $0.25 \mu \mathrm{m}$ in radius near 30 days and 80 percent after one-half year following the eruption.

Balloonborne measurements of volcanic aerosols following the Pinatubo eruption at Laramie [Deshler et al., 1992] show several tens of aerosol concentrations for radii greater than $0.15 \mu \mathrm{m}$ during July and August. These measurements might represent the edge of the volcanic cloud because the densest part had not arrived at the observational site, but the significant enhancement of aerosol concentration shows similar features to our model simulation. The number concentrations of residual volcanic aerosols observed with balloonborne instruments by Deshler et al. [1993] were still an order of magnitude higher than their ambient values in the lower stratosphere by 1 year after the eruption. The model 

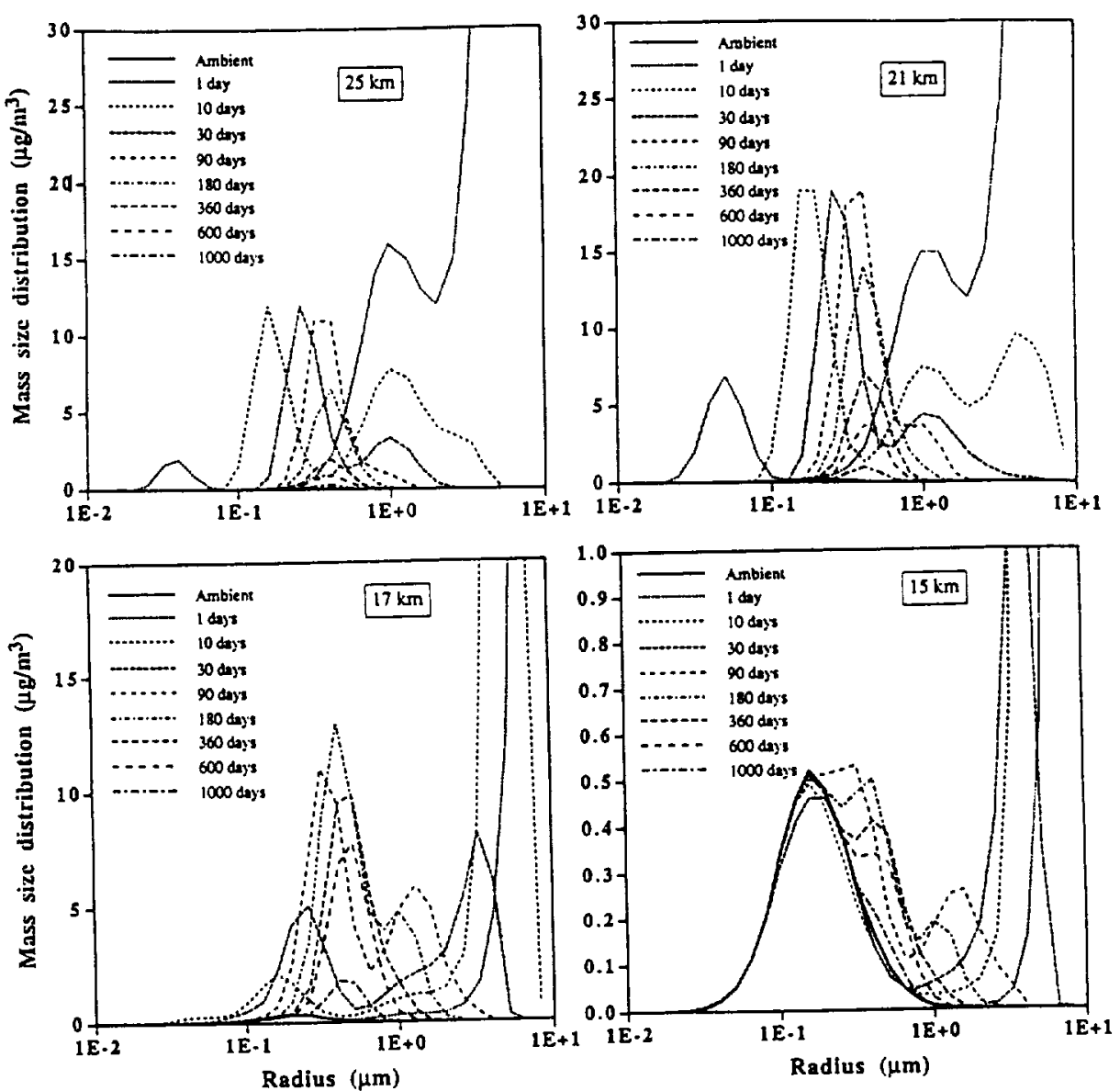

Figure 7. Aerosol mass size distributions simulated in the Pinatubo eruption plume with a onedimensional model. Read $1 \mathrm{E}-2$ as $1 \times 10^{-2}$.

simulations produce the reasonable magnitude of aerosol concentrations and vertical distributions, compared to the observed stratospheric aerosol increase following the Pinatubo eruption. The enhancement of stratospheric aerosols by the Pinatubo eruption persists for several years. The simulated decay rate of volcanic aerosols also indicate similar features as those of El Chichón's volcanic cloud measured by Hofmann et al. [1987].

\section{Mass Loading}

The simulated time series of aerosol mass mixing ratios for different altitudes is shown in Figure 10. Aerosol mass ratios have very high initial values resulting from the ash grain input and decrease dramatically as the large ash particles fall out. By a few months after the eruption, aerosol mass loading in the stratosphere from the volcanic eruption is dominated by sulfates (also see Figure 6), and the mass mixing ratios still exceed 100 parts per billion by mass (ppbm). The observed aerosol mass mixing ratios at Laramie, Wyoming $\left(41^{\circ} \mathrm{N}\right)$, in Figure 10 indicated that the maximum values are above $100 \mathrm{ppbm}$ and appear nearly 180 days after eruption. After about one-half year, the data fit with the model calculations very well although there is significant difference between model results and observations prior to that time. Obviously, the much lower observed
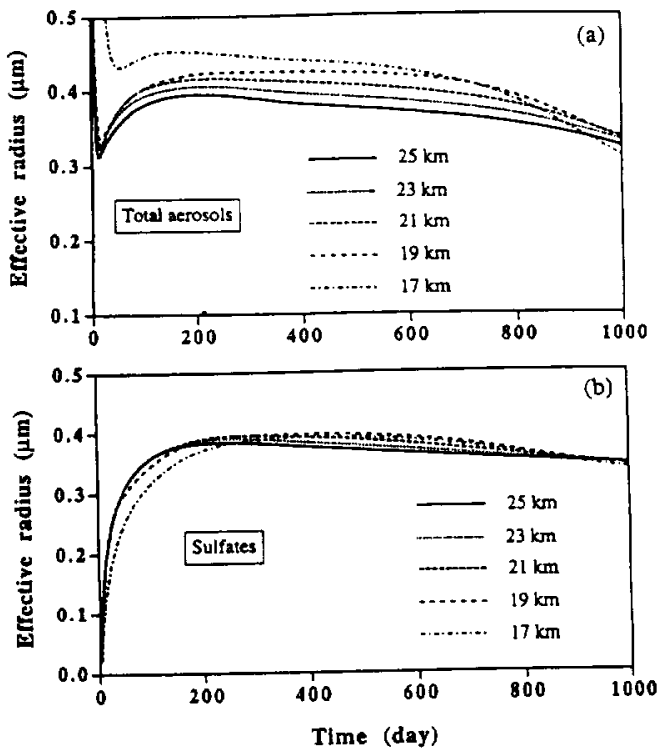

Figure 8. Variations of aerosol effective radii with time from 17 to $25 \mathrm{~km}$ simulated in the Pinatubo eruption cloud with a one-dimensional model: (a) for total aerosols, and (b) for pure sulfates (the second type of aerosols). 
mass mixing ratios (comparing to the model results) within the first few months were collected near the edge of the cloud because the densest part had not dispersed to middle latitude until one-half year. Hence the misfit between the model results and observations during that period results from inhomogeneities of the volcanic cloud. Nevertheless, the model simulation reasonably agrees with the data in aerosol mass mixing ratio after the cloud becomes relatively uniform.

Model results also show that the decay rate at higher altitude is faster than that at lower latitude. The highest values appear near $17-19 \mathrm{~km}$ after about 1 year following the eruption, which also agrees well with observations from Deshler et al. [1993]. Even at 600 days following the eruption the magnitude still exceeds 50 ppbm in the lower stratosphere, shown in both simulations and observations. The simulated aerosol mixing ratios have still not recovered their background values ( $\sim 0.4$ ppbm near $20 \mathrm{~km}$ ) after 1000 days of the eruption. The sulfate mass loading retrieved from aircraft measurements shows about an order of magnitude
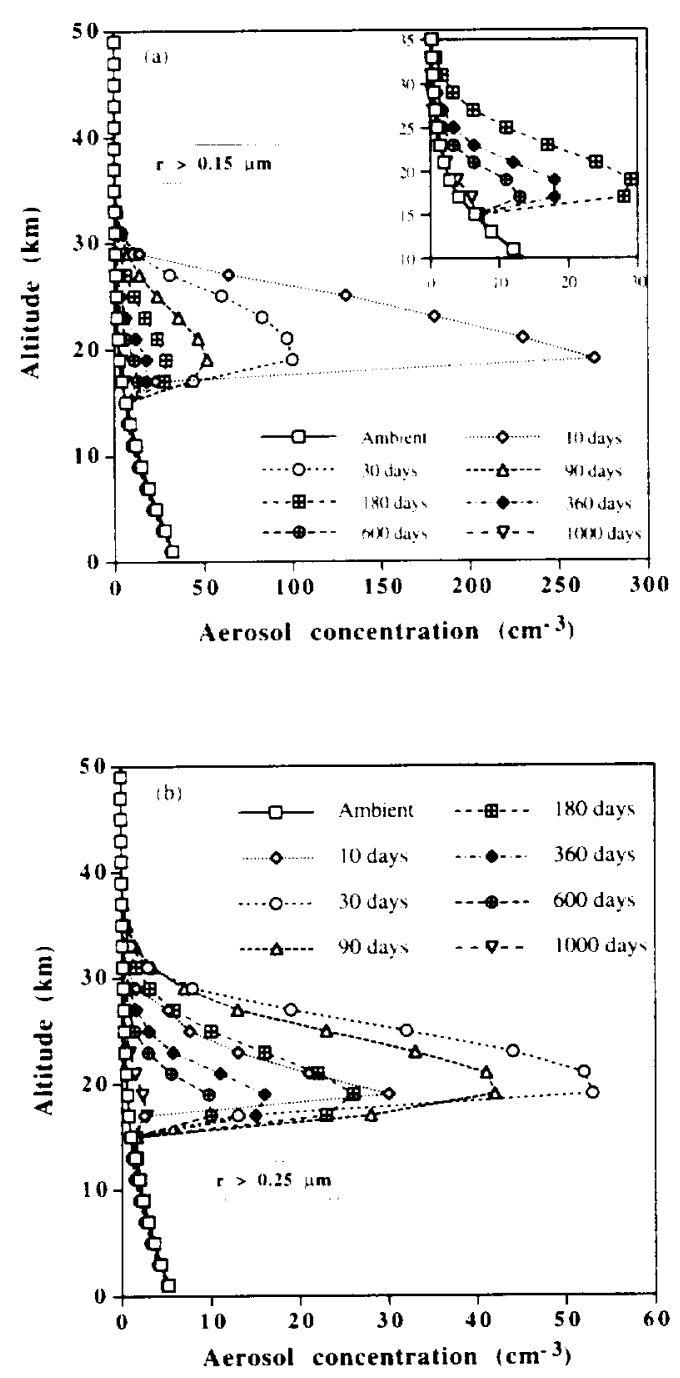

Figure 9. Vertical profiles of volcanic aerosol concentrations predicted for Pinatubo volcanic eruption cloud (a) for particle radii greater than $0.15 \mu \mathrm{m}$ and (b) for radii greater than $0.25 \mu \mathrm{m}$.

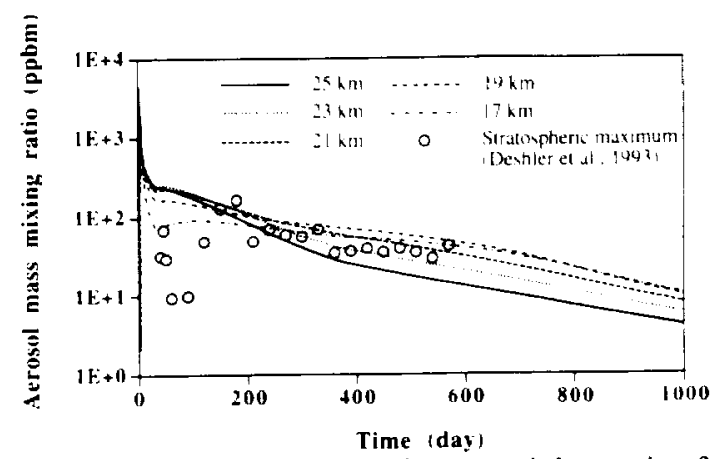

Figure 10. Variation in aerosol mass mixing ratios following the Pinatubo eruption, predictions (lines) at several altitudes and observations (circles) in the stratosphere [Deshler et al., 1993]. Read $1 \mathrm{E}+4$ as $1 \times 10^{4}$.

higher than background 2 years after the eruption. The model calculations are also consistent with these observations.

\section{Surface Area}

The changes of simulated aerosol surface areas over time (Figure 11) show some similar features to the changes in mass mixing ratios. The high initial values of simulated surface area drop rapidly during the first few weeks because of the efficient sedimentation of large ash particles and then gradually decay with time. The surface area at $17 \mathrm{~km}$ has a different behavior during the first few months, because the initial cloud was assumed between 20 and $30 \mathrm{~km}$. The predictions are generally comparable to the surface areas deduced from aerosol sample by Deshler et al. [1993] after about 6 months following the eruption. The measurements, however, exhibit large fluctuations and lower aerosol surface areas within one-half year compared with the model calculations. Again inhomogeneities in volcanic clouds and the fixed location of the observation site contribute to these differences at early times. After 5 to 6 months both measurements and model results reach a relative constant surface area of about $30-60 \mu \mathrm{m}^{2} / \mathrm{cm}^{3}$ between 17 and $21 \mathrm{~km}$. although some variations remain in the observational data apparently due to transient dynamic transport and seasonal processes. In addition, considerable increase of aerosol surface area near 500 days appears in the observational data. It is probably partially attributed to the dispersion of the aerosol loading from eruptions of Mount Spurr in Alaska $\left(61^{\circ} \mathrm{N}, 152^{\circ} \mathrm{W}\right.$, three eruptions have been reported on June 27. August 18, and September 16-17. 1992, with injection plumes penetrating into the stratosphere (Eos. Transactions, American Geophysical Union, volume 74, May 1993)).

Vertical profiles of the volcanic aerosol surface areas are shown in Figures $12 \mathrm{a}$ and $12 \mathrm{~b}$. The volcanic aerosols indicate a significant enhancement in surface area from the tropopause to $30 \mathrm{~km}$ both in simulation and observation. The estimation of surface area from lidar and aureolemeter measurements in Japan exceed $40 \mu \mathrm{m}^{2} / \mathrm{cm}^{3}$ in November and December (Figure 12b [Hayashida and Sasano, 1993]). The predictions (Figure 12a) of surface areas agree reasonably well with the vertical profiles retrieved from lidar and aureolemeter measurements; $40 \mathrm{\mu m}^{2} / \mathrm{cm}^{3}$ of surface area was also observed about 180 days after the Pinatubo eruption by balloonborne instrument [Deshler et al., 1993]. The 


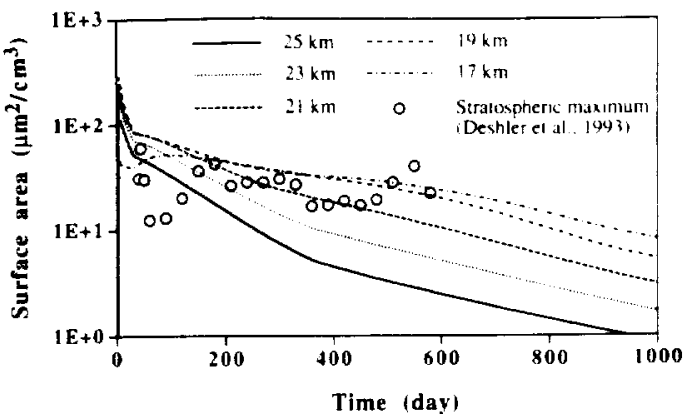

Figure 11. Variations in aerosol surface areas following the Pinatubo eruption, predictions (lines) at several altitudes and observations (circles) in the stratosphere [Deshler et al., 1993]. Note the apparent seasonal variations in the observations. Read $1 E+3$ as $1 \times 10^{3}$.

aerosol surface area increased at least tenfold above background values of $1 \mu \mathrm{m}^{2} / \mathrm{cm}^{3}$ and have remained elevated for 2-3 years. The enhancement in the aerosol surface area possibly causes measurable global ozone depletion in the stratosphere.

\section{Optical Properties}

The significant quantities of stratospheric sulfate aerosols generated by Pinatubo substantially perturbed atmospheric radiation and temperature. To determine the radiative properties of the volcanic aerosols, we use Mie theory to calculate extinction coefficients and optical depths for the simulated aerosol size distributions and vertical profiles as a function of time. The refractive index of sulfate aerosols is temperature and concentration dependent, but we use a constant value of 1.45-0i. The choice of refractive index has little effect on the calculated optical depth for the range of values that might be expected assuming either sulfuric acid or dust particles [Russell and Hamill, 1984].

The observational data show that the optical depth is wavelength dependent during the first month and becomes relative flat after 2 months (Figure 13a). The model optical depth (Figure 13b) also show distinct wavelength dependence within the weeks after the eruption, especially, on the day-one curve. After a few months, the model optical depth becomes much flatter (with less wavelength dependence). A significant wavelength dependence of the optical depth indicates the presence of small particles in the volcanic cloud. This relationship agrees with the evolution of the aerosol size distributions in the volcanic cloud discussed in the previous section. The model optical depths in the early time in Figure 13b exceed the observed values in Figure 13a because the early observations at Mauna Loa were sampling the edges of the dispersing volcanic clouds.

The calculated optical depths of the volcanic aerosols at a wavelength of $0.5 \mu \mathrm{m}$ (Figure 14) indicate an increase of 1 to 2 orders of magnitude from ambient values $(\sim 0.005)$ in the stratosphere. The simulated cumulative optical depths are in the range of $0.4 \sim 0.5$ during the first few months, resulting initially from ash and then from sulfates after about a few weeks. The vertical profile at 90 days shows the highest values among the others. The major contribution to this large value of optical depth is mainly contributed by sulfate particles because most ash has been removed from the stratosphere by that time. By a year after eruption, optical depths of volcanic aerosols are still as high as 0.1 (see the profiles at 360 days), and near 0.05 at 600 days at altitudes near $20 \mathrm{~km}$. Even by 1000 days after the eruption, the optical depths have not completely returned to their background values.

The time series of cumulative optical depth at different altitudes in the stratosphere is plotted in Figure 15. During the first few weeks, the optical depths appear up and down twice, resulting from the complexity of multimode size distributions including both ash particles and small sulfates and of spectrum changes due to removal and growth of different sized aerosols. By a month after the eruption, most contributions on optical depth are from sulfates. The cumulative optical depths reach their maximum values around 2-3 months and the values range between 0.14 and 0.55 from 25 $\mathrm{km}$ to $17 \mathrm{~km}$, and then decay with time in a consistent way as aerosol mass and surface area.

There are numerous measurements about volcanic aerosol optical properties observed at different wavelengths, altitudes, and latitudes following the Pinatubo eruption. The stratospheric optical depth in the months following the event was observed in the range between 0.2 and 0.5 [Stowe et al., 1992; Valero and Pilewskie, 1992; Russell et al., 1993a, b].
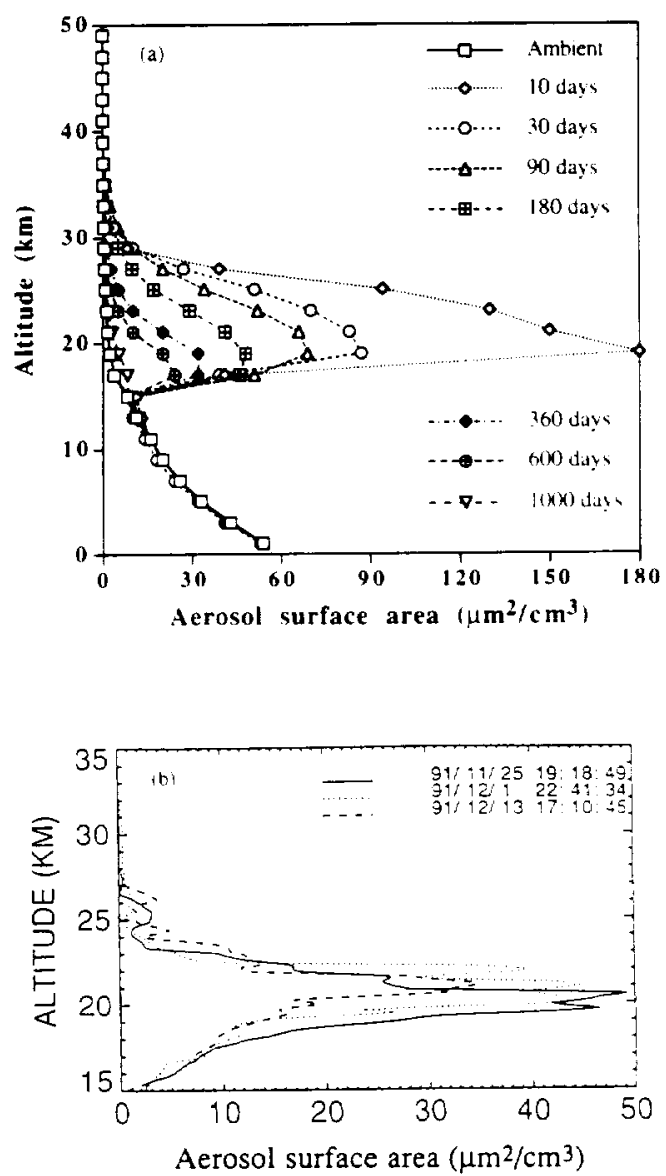

Figure 12. (a) Simulated vertical profiles of aerosol surface areas at different times after the Mount Pinatubo eruption. (b) The aerosol surface area of stratospheric aerosol on November 25, December 1, and December 13, 1991, estimated from the lidar and aureole meter measurements at $36.0^{\circ} \mathrm{N}, 140.1^{\circ} \mathrm{E}$ [Hayashida and Sasano, 1993]. 
The optical thickness derived from reflected solar radiation measurements (at $\lambda=0.5 \mu \mathrm{m}$ ) by the advanced very high resolution radiometer (AVHRR) on the NOAA 11 satellite show peak optical depths exceeding 0.5 at some locations during July and August 1991. A mean optical thickness of 0.31 was estimated on August 23 [Stowe et al., 1992]. Midvisible optical depths higher than 0.4 were observed from July 7 to 14, 1991 [Valero and Pilewskie, 1992]. The optical depth measured at Mauna Loa observatory by an Ames Research Center tracking sunphotometer was 0.2
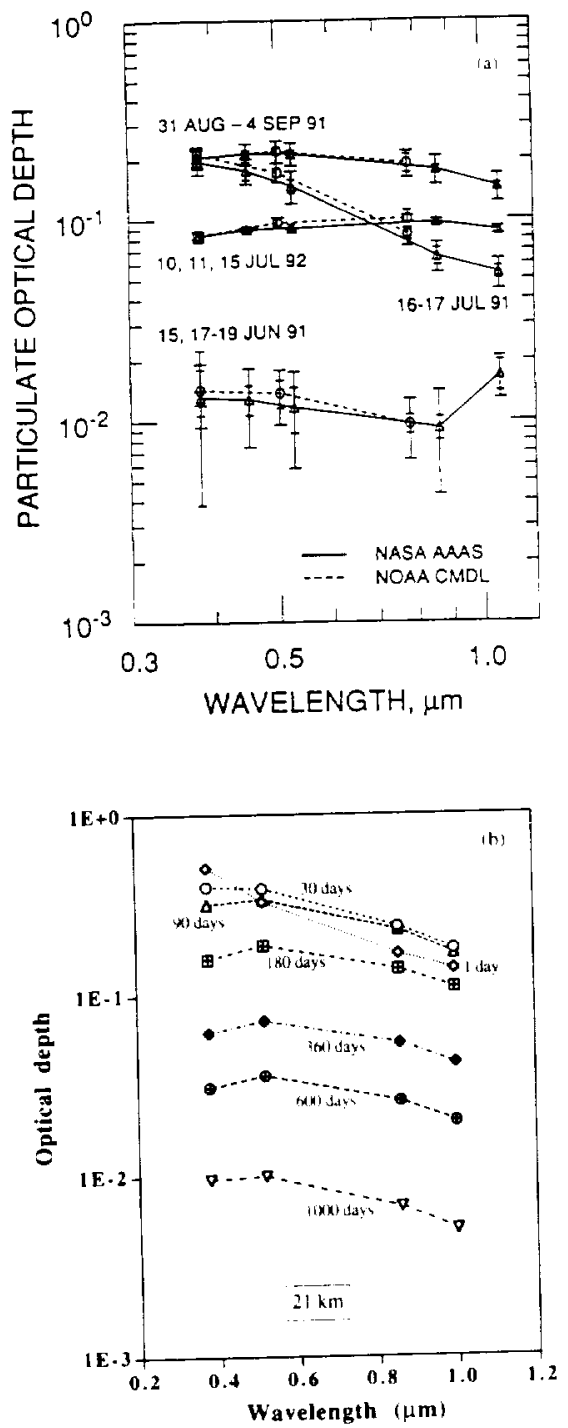

Figure 13. Total aerosol optical depths versus wavelength. (a) Observations at Mauna Loa observatory at different times following the Mount Pinatubo eruption on June 15 , 1991. The June 1991 data roughly correspond to background conditions but include substantial tropospheric aerosols. The July data show a strong wavelength dependence. The optical depths had a flat spectrum by August/September and were reduced about half value by July 1992 [Russell et al., 1993b]. (b) Model results, giving the optical depth spectrum for the total optical depth above $21 \mathrm{~km}$. Unlike the data in Figure 13a, tropospheric aerosol effects are not included. NASA American Association for the Advancement of Science, solid line; National Oceanic and Atmospheric Administration CMDL, dashed line. Read $1 \mathrm{E}+0$ as $1 \times 10^{\circ}$.

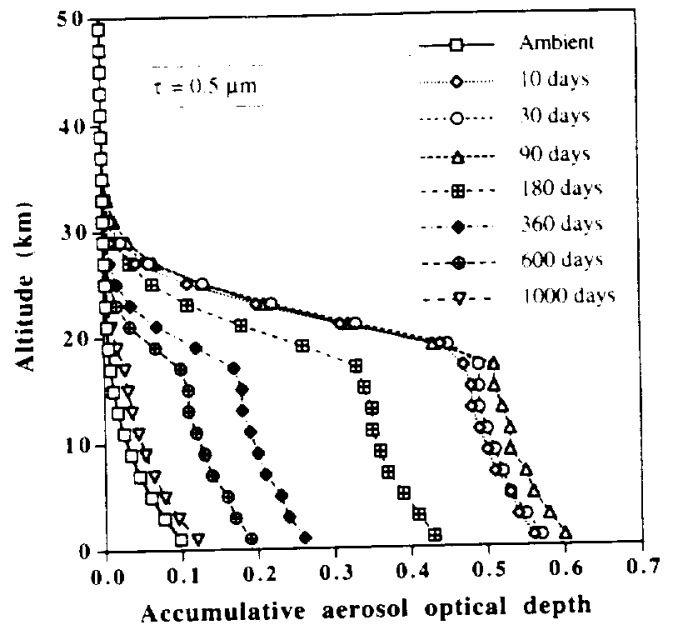

Figure 14. Vertical profiles of optical depth for the simulated Pinatubo volcanic clouds at different times after the eruption. The ambient optical depths are also shown for the background aerosol model. The aerosol optical depths are cumulative, from the top of the atmosphere. Hence the cumulative optical depth at each level represents the total optical depth of the aerosol lying overhead.

about 2 months after the Pinatubo eruption [Pueschel et al., 1992: Russell et al., 1993a]. In March 1992. optical depths as large as 0.22 were still observed over large areas in the stratosphere [Russell et al., 1993a]. The global average optical depth of Pinatubo aerosols (after the cloud dispersed over to the whole globe) was estimated about 0.15 in early 1992 [Sato et al., 1993]. Although our 1-D model calculations can not precisely compare with these measurements from different locations and altitudes collected with a variety of instruments, the basic features and magnitude of aerosol optical depth between model results and observations are very close and consistent. The significant increase in the atmospheric optical depth can produce measurable perturbations to global temperatures and even the general circulation of the stratosphere and troposphere. Stratospheric warming and surface cooling were observed during the year following Pinatubo [Angell. 1993]. Hansen et al. [1992] and Graf et al. [1992] predicted using general circulation model experiments that significant climatic impacts would result.

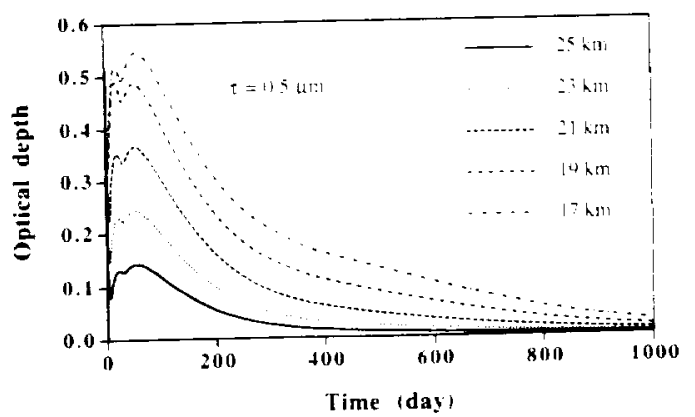

Figure 15. History of cumulative optical depths of Pinatubo volcanic aerosols predicted with the present model at different altitudes. 
and these have materialized in the form of a peak global cooling of about $0.5^{\circ} \mathrm{C}$.

\section{Conclusions}

A one-dimensional volcanic cloud model, including chemical and physical processes involving sulfate aerosols, was developed to study the formation and evolution of the Pinatubo eruption clouds in the stratosphere. By comparing model simulations to observations of the Pinatubo volcanic cloud, the model has been shown to reasonably reproduce the basic aerosol properties, including their size distribution, total mass and concentration, temporal and altitude variations, and radiative properties. The model, however, cannot reproduce the latitudinal variations observed throughout the several year evolution of the Pinatubo cloud.

The model includes all of the important aerosol formation processes in volcanic clouds. The $\mathrm{SO}_{2}$ injected by the volcanic eruption is transformed into sulfuric acid vapor by $\mathrm{OH}$ oxidation. The enhanced $\mathrm{H}_{2} \mathrm{SO}_{4}$ concentration creates new $\mathrm{H}_{2} \mathrm{SO}_{4} / \mathrm{H}_{2} \mathrm{O}$ particles through homogeneous nucleation. These fine droplets then evolve through condensational growth and coagulation. Model results show that the homogeneous nucleation of $\mathrm{H}_{2} \mathrm{SO}_{4} / \mathrm{H}_{2} \mathrm{O}$ droplets occurs within the first few weeks. Aerosol concentrations are subsequently controlled by coagulation. Condensational growth of the sulfate particles is altitude dependent and generally becomes insignificant about one-half year after the eruption. The effective radius of the stabilized volcanic sulfate aerosols is around $0.4 \mu \mathrm{m}$.

Clearly, the late-time density of a stratospheric eruption cloud is mainly determined by the sulfur gas emission. rather than the ash emission. The ash particles, which are quite large, fall out very quickly. The residual volcanic clouds are then composed mainly of $\mathrm{H}_{2} \mathrm{SO}_{4} / \mathrm{H}_{2} \mathrm{O}$ droplets generated in situ from the sulfur emissions. Homogeneous nucleation is essential for the production of new sulfuric acid particles. which are observed in the stratosphere. Our model calculations agree with observations indicating that more than $90 \%$ of the volcanic aerosols are completely volatile. It is the sulfate particles that reside in the stratosphere for several years and spread over the planet, greatly intensifying the Junge layer. The 2-D model study by Bekki and Pyle [1994] also indicated the importance of homogeneous nucleation. Without including homogeneous nucleation, the simulated timing of aerosol loading peak and the magnitude of the surface area exhibit significant differences from observations.

Simulated aerosol surface areas and mass mixing ratios within 2-3 years of the eruption are also comparable to those observed at $41^{\circ} \mathrm{N}$ by Deshler et al. [1993], but the observations indicate important variations associated with the latitudinal inhomogeneity of real volcanic clouds. Many of the measured parameters have lower values than predicted by the model during the first few months. Once the clouds have become relative uniform in the stratosphere, the agreement of the model with point observations improves. The aerosol surface areas in the lower stratosphere are still more than 10 $\mu \mathrm{m}^{2} / \mathrm{cm}^{3}$, comparable to the surface areas of polar stratospheric clouds, even 2-3 years after the Pinatubo eruption. This large enhancement in the aerosol surface has apparently led to measurable global ozone depletion in the stratosphere [Grant et al., 1992; Hofmann et al., 1993; Schoeberl et al. 1993].
Corresponding to the evolution of the aerosol size distribution in the volcanic clouds. the optical depths show a wavelength dependence within the first few weeks associated with a large number of small particles generated by homogeneous nucleation. A few months after the eruption, the wavelength dependence of the optical depth has become relatively flat, because the sulfate particles have grown to larger sizes through condensation and coagulation. In general, optical depths associated with volcanic sulfate aerosols in the model simulations remain at least an order of magnitude above ambient values during the first 2 years following the sulfur injection. Our model predictions are consistent with a variety of optical measurements following the eruption of Mount Pinatubo. The significantly enhanced optical depth would be expected to cause, and apparently has resulted in, observable global temperature perturbations as well as major chemical changes throughout the stratosphere.

The observed variability in aerosol properties can only be simulated with a multidimensional model. preferably in three dimensions. Such a model would allow the full range of observable conditions to be sampled numerically. These conditions include spatial structures (e.g.. vertical and horizontal), microphysical structures fe.g. . size distribution and optical depth variations), and chemical structures (e.g.. $\mathrm{SO}_{2}$ distribution and decay). Nevertheless, the general characteristics and long-term variations of the key parameters seem to be well reproduced by the present one-dimensional model. when an appropriate initialization is possible. Given that the present model treats all of the physical and chemical processes thought to contribute to the evolution of aerosol properties, although not the dynamical processes. and can generate all of the "observables" available from measurement systems, the next logical step, which we plan to take. would be to couple the volcanic aerosol model to a threedimensional model.

Acknowledgments. This work was partially upported by NASA grants NAG-1-1126 and NAGW-3721: School of Ocean and Earth Science and Technology, contribution $3 \times 17$. We uned the facility at NASA Ames and the San Diego Supercomputer Center for computations.

\section{References}

Angell. J. K.. Comparison of stratompherts warming following Agung. El Chichon and Pinatubo rakianis eruptorn. Gerophss. Res. Lett. 20,715-718. 1993.

Bekki. S., and J. A. Pyle. A two-dimenuional modeling study of the volcanic eruption of Mount Pinatuha, J. Gaphlss. Res.. 99. $18.861-18.869 .1994$.

Bluth, G. J. S.. S. D. Doiron. C. C. Schnetzler. A. J. Krueger. and L. S. Walter. Global Tracking of the $S(O)$ cloud from the June. 1991. Mount Pinatubo eruptions. (jevphys. Res. Lott. 19. 151154, 1992.

Boville, B. A.. J. R. Holton, and P. W. Mote. Simulation of the Pinatubo aerosol cloud in general circulation model. Gerphss. Res. Lett., 18, 2281-2284. 1991.

Brasseur. G., and C. Granier. Mount Pinatuho aerosols. chlorofluorocarbons, and ozone depletion. Sichere. 25, 1239-1242. 1992.

Brasseur, G.. and S. Solomon. Aermomy of the lidale Amosphere. D. Reidel. Norwell. Mass.. 1986

Cadle. R. D. Some effects of the emissions of explosive volcanoes on the stratosphere, $J$. Geophs. Re.. 85. $4495-498.1980$

Cadle, R. D., C. S. Kiang. and J.-F. Louis. The global scale dispersion of the eruption clouds from major volcanic eruptions. J. Geophys. Res.. 81. 3125-3132. 1976.

Cadle. R. D. , F. G. Fernald, and C. L. Frush. Combined use of lidar 
and numerical diffusion models to estimate the quantity and dispersion of volcanic eruption clouds in the stratosphere: Vulcan Fuego, 1974 and Augustine, 1976, J. Geophys. Res., 82. 17831786. 1977.

Capone, L. A., O. B. Toon, R. C. Whitten, R. P. Turco, C. A. Riegel, and K. Santhanam, A two-dimensional model simulation of the El Chichón volcanic eruption cloud. Geophys. Res. Lett.. 10. 1053-1056, 1983.

Crutzen, P. J.. The possible importance of OCS for the sulfate layer of the stratosphere, Geophys. Res. Lett., 3, 73-76, 1976.

DeMore, W. B., S. P. Sander, D. M. Golden, R. F. Hampson, M. J. Kurylo, C. J. Howard, A. R. Ravishankara, C. E. Kolb. and M. J. Molina, Chemical kinetics and photochemical data for use in stratospheric modeling, JPL Publ. 90-1, Pasadena, Calif., 1991.

Deshler, T., D. J. Hofmann, B. J. Johnson, and W. B. R. Rozier, Balloonborne measurements of the Pinatubo aerosol size distribution and volatility at Laramie, Wyoming, during the summer of 1991, Geophys. Res. Lett., 19, 199-202, 1992.

Deshler, T., B. J. Johnson, and W. B. R. Rozier, Balloonborne measurements of Pinatubo aerosol during 1991 and 1992 at $41^{\circ} \mathrm{N}$ : Vertical profiles, size distribution, and volatility. Geophys. Res. Lett., 20, 1435-1438, 1993.

Farlow, N. H., V. R. Oberbeck, K. G. Snetsinger, G. V. Ferry, G. Polkowski, and D. M. Hayes, Size distribution and mineralogy of ash particles in the stratosphere from eruption of Mount St. Helens, Science, 211, 832-834, 1981.

Goodman, J., K. G. Snetsinger, R. F. Pueschel, G. V. Ferry, and S. Verma, Evolution of Pinatubo aerosol near $19 \mathrm{~km}$ altitude over western North America, Geophys. Res. Lett., 21, 1129-1132, 1994.

Graf, H.-F., I. Kirchner, A. Robock, and I. Schult, Pinatubo eruption winter climate effects: Model versus observations, Rep. 94, 24 pp., Max-Planck-Inst. für Meteorol., Hamburg, Germany, 1992.

Grant, J., et al., Observations of reduced ozone concentrations in the tropical stratosphere after the eruption of Mt. Pinatubo. Geophys. Res. Lett., 19, 1109-1112. 1992.

Hansen, J.. A. Lacis, R. Ruedy, and M. Sato, Potential climate impact of Mount Pinatubo eruption, Geophys. Res. Lett., 19. 215-218, 1992.

Hayashida, S., and Y. Sasano. Stratospheric aerosol change in the early stages of volcanic disturbance by the Pinatubo eruption observed over Tsukuba, Japan, Geophys. Res. Lett., 20, 575-578. 1993.

Hofmann. D. J., Perturbations to the global atmosphere associated with the El Chichón volcanic eruption of 1982, Rev. Geophys., 25, 743-759, 1987.

Hofmann, D. J., and J. M. Rosen, Sulfuric acid droplet formation and growth in the stratosphere after the 1982 eruption of El Chichón, Science, 222. 325-327, 1983.

Hofmann, D. J., and J. M. Rosen, On the temporal variation of stratospheric aerosol size and mass during the first 18 months following the 1982 eruptions of El Chichon, J. Geophys. Res., 89 . $4883-4890,1984$.

Hofmann, D. J., J. M. Rosen, J. W. Harder, and S. R. Rolf, Observations of the decay of the El Chichon stratospheric aerosol cloud in Antarctica, Geophys. Res. Lett., 14, 614-617, 1987.

Hofmann, D. J., S. J. Oltmans, S. Harris, W. D. Komhyr, J. A. Lathrop, T. DeFoor, and D. Kuniyuki, Ozonesonde measurements at Hilo. Hawaii, following the eruption of Pinatubo, Geophys. Res. Lett., 20. 1555-1558, 1993.

Jäger, H., The Pinatubo eruption cloud observed by lidar at Garmisch-Partenkirchen, Geophys. Res. Lett., 19. 191-194, 1992.

Johnston, P. V., R. L. McKenzie, J. G. Keys, and W. A. Matthews, Observations of depleted stratospheric $\mathrm{NO}_{2}$ following the Pinatubo volcanic eruption, Geophys. Res. Lett., 19, 211-213. 1992.

Junge, C. E., C. W. Chagnon, and J. E. Manson, Stratospheric aerosols, J. Meteorol.. 18, 81-108, 1961.

Labitzke, K., and M. P. McCormick, Stratospheric temperature increases due to Pinatubo aerosols, Geophys. Res. Lett., 19, 207-210. 1992.

Mankin, W. G., M. T. Coffey, and A. Goldman. Airborne observations of $\mathrm{SO}_{2}, \mathrm{HCl}$ and $\mathrm{O}_{3}$ in the stratospheric plume of the Pinatubo Volcano in July 1991, Geophys. Res. Lent, 19, 179-182, 1992.
McCormick, M. P. anj R. E. Veiga, SAGE II measurements of early Pinatubo aerosols, Geophys. Res. Lett.. 19, 155-158. 1992.

McPeters, R. D., Global measurements of $\mathrm{SO}_{2}$ from Pinatubo, the conversion to aerosol. and the resulting ozone effects (abstract), Eos Trans. AGU, 73(43). Fall Meeting Suppl., 631. 1992

Pinto. J. P., R. P. Turco. and O. B. Toon. Self-limiting physical and chemical effects in volcanic eruption clouds. J. Geophys. Res.. $94,11.165-11.174,1989$.

Pitari. G., A numerical study of the possible perturbation of stratospheric dynamics due to Pinatubo aerosols: Implication for tracer transport, J. Atmos. Sci, 50, 2443-2461, 1993.

Pueschel, R. F., K. G. Snetsinger, P. B. Russell, S. A. Kinne, and J. M. Livingston. The effects of the 1991 Pinatubo volcanic eruption on the optical and physical properties of stratospheric aerosols, in Proceedings, IRS92: Current Problems in Atmospheric Radiation, edited by S. Keevalik. A. Deepak. Hampton. Va., 1992.

Read, W. G., L. Froidevaux, and J. W. Waters. Microwave LiMB sounder measurement of stratospheric $\mathrm{SO}_{2}$ from the Mt. Pinatubo volcano. Geophys. Res. Lett., 20, 1299-1302, 1993.

Russell. P. B., and P. Hamill, Spatial variation of stratospheric aerosol acidity and model refractive index: Implication of recent results, J. Atmos. Sci., 4l, 1781-1790, 1984.

Russell. P. B., et al., Post-Pinatubo optical depth spectra vs. latitude and vortex structure: Airborne tracking sunphotometer measurements in AASEII, Geophys. Res. Lett.. 20, 2571-2574, 1993a.

Russell. P. B., et al., Pinatubo and pre-Pinatubo optical depth spectra: Mauna Loa measurements, comparisons, inferred particle size distributions, radiative effects, and relationship to lidar data, J. Geophys. Res., 98, 22.969-22.985. 1993 b.

Sato, M. J. E. Hansen, M. P. McCormick, and J. B. Pollack. Stratospheric aerosol optical depth, 1850-1990. J. Geophys. Res.. 98. 22,987-22.994, 1993 .

Schoeberl, M. R.. P. K. Bhartia, and E. Hilsenrath, Tropical ozone loss following the eruption of Pinatubo, Geophys. Res. Lett.. 20. 29-32. 1993.

Sheridan, P. J., R. C. Schnell, D. J. Hofmann, and T. Deshler, Electron microscope studies of Mt. Pinatubo aerosol layers over Laramie, Wyoming, during summer 1991. Geophys. Res. Letr., 19. 203-206, 1992.

Stowe. L. L.. R. M. Carcey, and P. P. Pellegrino, Monitoring the Mt. Pinatubo aerosol layer with NOAA/11 AVHRR data, Geophys. Res. Lett.. 19, 159-162, 1992.

Thomason. L. W. . Observations of a new SAGE II extinction mode following the eruption of Mt. Pinatubo, Geophys. Res. Leth.. 19. 2179-2182, 1992.

Tie. X.. X. Lin, and G. Brasseur. Two-dimensional coupled dynamical/chemical/microphysical simulation of global distribution of $E$ Chichón volcanic aerosols. J. Geophys. Res.. 99. 16.779-16.792. 1994

Toon, O. B., R. P. Turco, P. Hamill. C. S. Kiang. and R. C. Whitten. The NASA Ames Research Center stratospheric aerosol model. Il. Sensitivity studies and comparison with observations. NASA Tech. Rep.. 1363. 1979a.

Toon. O. B.. R. P. Turco. P. Hamill. C. S. Kiang. and R. C. Whitten, A one-dimensional model describing aerosol formation and evolution in the stratosphere. 2. Sensitivity studies and comparison with observations. J. Atmos. Sci.. 36. 718-736. $1979 \mathrm{~b}$.

Toon, O. B., R. P. Turco, D. Westphal. R. Malone, and M. S. Liu. A multidimensional model for aerosols: Description of computational analogs. J. Atmos. Sci., 45, 2123-2143, 1988.

Turco, R. P. Volcanic aerosols: Chemistry, microphysics, evolution and effects, in Volcanism-Climate Interactions. NASA Conf. Publ. 10062, D1-D30, 1990.

Turco, R. P., P. Hamill, O. B. Toon. R. C. Whitten, and C. S. Kiang, The NASA Ames Research Center stratospheric aerosol model, I, Physical processes and numerical analogs. VASA Tech. Rep., 1362. 1979a.

Turco, R. P. P. Hamill, O. B. Toon. R. C. Whitten. and C. S. Kiang, A one-dimensional model describing aerosol formation and evolution in the stratosphere. 1. Physical processes and mathematical analogs, J. Atmos. Sci.. 36. 699-717. 1979 b.

Turco, R. P., O. B. Toon. and R. C. Whitten. Stratospheric aerosols: Observation and theory, Rev. Geophys., 20, 233-279. 1982. 
Turco, R. P., O. B. Toon, R. C. Whitten. P. Hamill, and R. G. Keesee, The 1980 eruptions of Mount St. Heiens: Physical and chemical processes in the stratospheric clouds. J. Geophys. Res. $88,5299-5319,1983$.

Valero, F. P. J., and P. Pilewskie, Latitudinal survey of spectral optical depths of the Pinatubo volcanic cloud-derived particle sizes, columnar mass loading, and planetary albedo. Geophys. Res. Lett. 19, 163-166, 1992.

Woods, A. W., and S. Self. Thermal disequilibrium at the top of volcanic clouds and its effect on estimates of the column heights. Nature, 355, 628-630, 1992.

Young, E. R., H. Houben, and O. B. Toon, Radiatively forced dispersion of the Mt. Pinatubo volcanic cloud and induced temperature perturbations in the stratosphere during the first few months following the eruption, Geophys. Res. Lett., 21. 369-372, 1994.
Zhao, J.-X., Numerical studies of the stratospheric aerosol I. under backgroul. 1 and perturbation conditions. Ph.D. dissen. tion. $218 \mathrm{pp}$.. Univ, of Calif., Los Angeles, 1993

O. B. Toon. NASA Ames Research Center, Moffelt Field. CA 94035.

R. P. Turco. Department of Atmospheric Sciences. University of California, Los Angeles. CA 90024.

J. Zhao (corresponding author). Department of Meteorology. School of Ocean and Earth Science and Technology. University of Hawaii, Honolulu. H1 96822 .

(Received September 8. 1994; revised December 8. 1994: accepted December 8, 1994.) 